\title{
Student Involvement for Student Success: Student Staff in the Learning Commons
}

\author{
Julie Mitchell and Nathalie Soini
}

\begin{abstract}
How do you effectively train and assess student staff in a learning commons environment? How do you foster a student-led approach while maintaining accurate and high-level service? How do you create an environment where student staff are engaged and motivated to succeed? Peer-to-peer service models are fundamental to many learning commons environments and contribute to student success. Many student-delivered services in learning commons compliment programs traditionally offered exclusively by professional staff such as librarians, IT professionals, learning specialists or student affairs personnel. In such service models, students are the front line contact and the need for knowledgeable assistance and accurate referrals remains paramount. This article presents the findings of a study that investigated how training and assessment is approached with student staff in a learning commons environment. Learning commons coordinators and supervisors from across North American shared how they train students (methods and content), approach ongoing professional development of student staff, and how they monitor or assess the overall quality and accuracy of their student service models. The survey results and tangible examples offer insights and strategies for fostering an engaged student team, driven to deliver a high level of service.
\end{abstract}

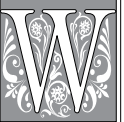

hether the space is called a learning commons or an information commons, new and innovative learning environments are pervasive in academic libraries across North America. These spaces often combine advanced technology, learning support, and collaborative work areas and emphasize a learner- or student-centered approach to services. Since the early 2000s, much has been written with respect to design of learning commons spaces, planning of services, and implementation of technology; however, there is little focus in the literature on training staff to work in a learning commons environment. As noted by Lippincott, ${ }^{1}$ "[ $\left.\mathrm{t}\right]$ he range of services in an information commons is broader than in a traditional reference area." Consequently, with a

Julie Mitchell is Managing Librarian for the Chapman Learning Commons in the Irving K Barber Learning Centre at the University of British Columbia, e-mail: julie.mitchell@ubc.ca; Nathalie Soini is Learning Commons Coordinator at Queen's University, e-mail: soinin@queensu.ca. (c) 2014 Julie Mitchell and Nathalie Soini, Attribution-NonCommercial (http://creativecommons.org/licenses/by-nc/3.0/) CC BY-NC 
broader range of services in place, there are broader training requirements for learning commons staff.

The Queen's University Learning Commons and the University of British Columbia's (UBC) Chapman Learning Commons each have a long history of employing students to deliver exceptional service in support of student academic success. Since 2002, UBC's Chapman Learning Commons has hired a core team of students to offer learning technology support and referral to library and learning support services, including reference and circulation; tutoring; writing support and peer academic coaching. Since 2005, the Queen's Learning Commons has hired a team of students to offer technical support and referral to all Learning Commons partners, including the Library, IT Services, the Writing Centre, Learning Strategies and the Adaptive Technology Centre. Both Queen's and UBC train new students each year to provide help and answer questions at a central desk, and librarians at both institutions have struggled in developing a comprehensive training program that would prepare students for the diverse and complex questions that they receive at their service desk. In developing and evolving their training programs, many questions arose, such as: What are the core training areas that learning commons students should receive? What are the best methods for delivering training? How can we maintain high-quality service and provide adequate support to ensure questions are answered accurately?

To answer these questions, the learning commons librarians at Queen's and UBC collaborated on an exploratory study to identify the trends with respect to student hiring, training, and staffing in learning commons across North America. This initial study was meant to build on the professional experiences of the authors and to identify future research in this field. The following paper presents findings from this research study, which explores the standard topics of student training; the format and frequency of training; staffing models; and strategies that supervisors use to ensure the accuracy of information provided by student staff. The findings of the research suggest that, although learning commons environments differ in many respects, there is a commitment to high-quality training and support of student staff, as well as common content areas with respect to training. Whether you are developing a new training program for your learning commons or hoping to reinvigorate an existing training program, the results from this study provide useful insights for delivering training to and working effectively with student staff teams.

\section{Literature Review}

The concept of hiring student staff is not unique to learning commons - there is a long history in the academic library environment of employing student workers to staff service desks. Faix et al. highlight a 1975 article in College and Research Libraries outlining the results of a survey indicating that use of nonprofessional staff at the reference desk was common. ${ }^{2}$ Stanfield and Palmer note that literature in the late 1960s and 1970s indicate a willingness to allow student workers to take on more sophisticated tasks at the reference desk. ${ }^{3}$ A commonly cited article is one by Heinlen, asserting that certain references duties could be successfully performed by student assistants who were properly trained and supervised. ${ }^{4}$

As early as the 1950s, evidence of peer leadership on university and college campuses is also documented in the student services literature, originating with students working in residence life and orientations. ${ }^{5}$ In an article on the emergence of peer education and peer leadership roles in student services, Ganser and Kennedy review the extensive history of undergraduate students serving in peer leader roles within higher education. In addition to documenting the origins of peer leadership, the article highlights evidence regarding the positive impact of these roles on student success, 
including "increased satisfaction, persistence and retention, social development and academic performance." 6

While the literature on training learning commons student staff is limited, there are many articles pertaining to working with students in academic libraries and other campus environments that offer insights relevant to working with student staff in a learning commons. By reviewing the library and student affairs literature, the benefits, challenges, and common training approaches to working with student staff and peer leaders are highlighted and ideas emerge for training and working effectively with learning commons student staff specifically.

\section{Benefits of Student Staff Teams}

A typical approach in an academic library is to staff the reference desk with trained paraprofessionals and student workers who are capable of answering basic library and directional questions and will refer complex questions to a librarian. ${ }^{7}$ The advantage of this approach, often highlighted in library literature, is that less complex questions are screened by student and paraprofessional staff first, thereby freeing up librarian time to offer higher-quality reference for in-depth queries. ${ }^{8}$ Student staff are also available to work later, allowing the library or learning commons to be open extended hours beyond the typical workday of a professional staff member.

Another benefit to hiring student staff, as highlighted in the literature, is the benefit of the peer-to-peer model. Multiple articles on peer-to-peer service in a learning commons environment acknowledge that students are often more comfortable approaching fellow students than a professional or authority figure for assistance. ${ }^{9}$ In fact, even as early as 1970, Young noted that "some students were able to relate more effectively to a peer than to a professional."10 Similarly, Cuseo notes that "peers may elicit involvement of freshman students more effectively because they are not perceived as intimidating as authority figures."11 Peer-based support or peer leadership is the foundation for many learning commons service models, and, as noted by $\mathrm{O}^{\prime}$ Neil and Comley, "[t]he trend of university libraries moving to information or learning commons appears in many cases to have been accompanied by an expansion of the role of student employees." ${ }^{12}$

Looking beyond the library literature, student affairs or student services research offers important insights for fully understanding the benefits of peer leadership. As noted by Shook and Keup, the benefits of peer leadership are three-fold: peer leadership positively impacts the students the peer leaders work with, the peer leaders themselves, and the institution as a whole. ${ }^{13}$ For example, from the student perspective, peer leaders are closest to the student experience and may notice issues sooner than professional staff. And when provided with thorough training, peer leaders can be an expert source of referral for fellow students. Peer leaders can assist fellow students in finding their niche on campus, discover new opportunities, and connect them with friends, support groups, and resources that reduce the stress of transition to university life. ${ }^{14}$

From the peer leader's perspective, these roles encourage engagement and involvement with the campus community; create a greater sense of awareness around resources; create meaningful interactions with peers, staff, and faculty; and create a stronger sense of belonging and a desire to persist. ${ }^{15}$ The benefits for the students in peer leadership positions may also extend beyond the university, as evidence indicates “employers and corporate recruiters place considerable weight on student extracurricular involvement during college, particularly leadership positions, in making hiring decisions." ${ }^{16}$ From the perspective of the institution, peer leadership can provide a cost-effective solution to meet demands for student assistance on a large campus, it can be a valuable channel for dissemination information to the campus community, and it can contribute to persistence and completion at college or university. ${ }^{17}$ The importance 
of peer leaders to the institution is captured succinctly by Sullivan, who notes that "[s] tudents, as individuals and in groups, are not only the recipients of our services but also critical partners in the achievement of institutional goals." ${ }^{18}$

As noted by Astin, ${ }^{19}$ holding a part-time job on campus (such as a peer leader in a learning commons) is an important factor that impacts student retention. Astin argues that this is due to the level of student involvement created by such jobs, since spending more time on campus results in increased likelihood of connecting with other students, faculty members, or staff. Astin's highly influential Theory of Student Involvement argues that the greater the student's involvement in college, the greater the impact on student learning and personal development. ${ }^{20}$ While part-time jobs may reduce the discretionary time available to students to study, Pascarella and Terenzini note that, for many college students, employment may provide "a context in which [students] can acquire efficient organizational skills and work habits." 21

As documented in the library and student affairs literature, there are numerous benefits to working with student staff and engaging the peer leadership model in supporting students. Employing students frees up librarian time, allows the library to be open later, and provides benefits to students, peer leaders, and the institution overall.

\section{Challenges with Student Staff Teams}

While there are many benefits of hiring students in a library or learning commons, there are also many challenges, primarily due to the relatively high turnover of student employees. With respect to their student assistant program at Victoria University Library, O'Neil and Comley note that "the cycle of recruitment, induction and turnover; and integration of student employees into the main business of the organization" can be a challenge for student assistant programs. ${ }^{22}$ Similarly, with respect to their student assistant program at Valparaiso University, Connell and Mileham point out that "[s] tatistics show a committed student staff after hiring but graduation, internships, and semesters spen[t] studying abroad results in a relatively high turnover." ${ }^{23}$ The high turnover of student staff in a learning commons environment has implications for training - the duration, frequency, and format of training are all important points to consider in shaping a training program when students may only be around for a semester, an academic term, or a year.

Other issues that stem from hiring students are highlighted by Stanfield and Palmer, such as financial aid budgets, unions, retention, punctuality, attendance, and students socializing with friends while on shift. ${ }^{24}$ Faix et al. echo the issue about funding and budgets with regard to keeping student staff and for consistent staffing at the desk. ${ }^{25}$ While budget issues will remain an ongoing concern in today's economy, issues such as punctuality, attendance, and student staff professionalism at the desk can all be addressed by developing well-designed training programs and creating a supportive work environment for student staff.

As documented in the student affairs literature, another challenge in working with student staff is the issue of overcommitment of the peer leaders. While the benefits of these positions are well documented, these benefits decrease if students are involved to the point of overcommitment. For example, as noted by Ganser and Kennedy, the 2009 National Survey of Peer Leadership showed that students held between two to three peer leadership positions during their college career. ${ }^{26}$ Further, 44 percent of respondents held more than one peer leader position at a time, while 8 percent held four or more simultaneously. While capacity of each student may vary, it is important for learning commons professionals to be mindful of other peer leadership commitments that student team members may have to avoid scheduling conflicts, overcommitment, and potential burnout of their student staff. 


\section{Approaches to Training Student Staff}

Much of the literature about student staff focuses on training students so that they may deliver a high level of service. Training student staff effectively is fundamental to the success of a learning commons service point, where students are often the primary contact with patrons. As noted by Faix et al., undergraduate students are still developing as professionals and are "often not skilled researchers." 27 This is particularly notable given that service on a library or learning commons desk demands a high level of professionalism and often a sophisticated and diverse skill set to answer or even refer questions correctly. In an analysis of articles from the 1970s onward, Stanfield and Palmer observe a common theme that, if student workers were going to perform higher order tasks in libraries, "thorough and ongoing training [is] essential." ${ }^{28}$ Connell and Mileham also observe that, in an "ever-evolving library ... training is an ongoing project." ${ }^{29}$ In addition, with the expanded role of students in a learning commons environment, it is no longer common to have a librarian to whom to refer questions, and, with many learning commons open extended hours, students may be working alone. Given these circumstances, training students adequately is essential for ensuring quality service in a learning commons environment.

With the emphasis on the importance of training, how is it approached in library or learning commons environments? There are numerous books and articles that present how-to guides for hiring, training, and working with student staff in libraries. For example, Kathman's book Managing Student Employees in College Libraries ${ }^{30}$ details how to approach training and orientation; create and implement policies; and evaluate student staff. A seminal article for many learning commons librarians is Borin's "Training, Supervising and Evaluating Student Information Assistants." 11 In her article, Borin outlines key skill areas to look for when hiring; critical topics to include in training; and approaches to supervision and evaluation. For example, supervisors need to note that:

... the student will not know how to recognize when a more complicated question is concealed within a general or directional question. The second, related, concern is that a student may not refer a question or ask for help when necessary. These concerns can be answered through a training process that focuses on providing training in reference interview techniques. ${ }^{32}$

Overall, the theme that emerges from these books and articles is that thorough and well-designed training as well as ongoing feedback and supervision of student staff is essential for success of the students in the position and for ensuring a high standard of service delivery.

Although academic librarians and their staff appear to be the primary trainers of student staff in the learning commons, some of the literature points to the fact that certain learning commons are looking or should be looking to a cross-training approach for their students. The idea of cross-training means that more than one learning commons partner or other campus units contribute to and participate in the training of the student staff. Of particular interest is the example in Adams and Young's article, where they discuss their institution's cross-training experience with student staff in their learning commons at the Harrisburg University of Science and Technology in Pennsylvania. They explain that:

IT, library, and student services work in partnership to cross-train a group of students in customer service, basic information technology tasks such as assisting students with accessing the wireless network and printers, basic library skills 
such as searching the catalog, familiarity with searching the library's licensed databases, and academic skills such as avoiding plagiarism and citing sources. ${ }^{33}$

This particular program at Harrisburg is run by student services and is part of their "Model Student Program." ${ }^{34}$ Other examples of cross-training can also be found in articles by Faix et al. and Stanfield and Palmer. ${ }^{35}$ A cross-training approach that brings together multiple campus units may also help break down the "silos" that form at large academic institutions, lead to more accurate referrals, and facilitate a more seamless experience for students. ${ }^{36}$

An interesting result from the 2005 National Peer Educator Survey is that peer educators on average participated in seventeen hours of training and are trained on a variety of topics; however, some peer educators are speaking with students on topics for which they have not received training. ${ }^{37}$ As noted by Shook \& Keup, "[p]eer leaders serve most effectively in the capacity as a referral agent when they are provided appropriate training to refer their peer to the available campus resources and when this training regime models effective resource referral practices." ${ }^{38}$ Latino and Unite also emphasize that intentional and ongoing training is perhaps the most important aspect of a successful peer education program. ${ }^{39}$ In addition to the importance of providing thorough training, it is also important to acknowledge the benefits to the student leader in receiving such training. The extensive training that often occurs in many peer leadership programs in many ways mimics the content of first-year or freshman seminar courses by increasing knowledge of campus resources and strategies for student success such as note-taking, time management, library research, exam-taking, and communication skills. Extensive research supports that these freshman seminar courses help with student retention and academic success. ${ }^{40}$

Despite the emphasis in the literature on the importance of training student staff and peer leaders, the value of investing librarian time in training students may be overlooked by academic libraries in practice. Curran points out that:

Over the past 15 to 20 years of cutbacks and retrenchment, coaching and training, which used to be gratifying tasks, came to be viewed as onerous, timeconsuming "impositions" by academic librarians. Those being trained were likely to be part-time or student librarians who would leave the organization as soon as their contracts ended or when a permanent position became available elsewhere. Orientation, mentoring, counselling, training and sponsoring-crucial components of retention - all but disappeared in the flurry of daily working life. Academic libraries that have not revived these practices need to devote more time and energy to them. ${ }^{41}$

Curran's quote is particularly important for learning commons librarians, coordinators, or supervisors who may need to advocate for resources to support training student staff, particularly with shrinking library budgets. Training students can be a significant time investment and is an ongoing process of coaching, mentorship, and skilled supervision. Stanfield and Palmer remarked that "[1]ibrarians must consider an investment in time to plan for new and different models of service that involve student workers more deeply, and for training student workers in ways that will lead them in the direction of performing higher order tasks in reference and information services." 42

While select examples and models exist in the literature with respect to training students to work in a learning commons environment, many questions remain that have implications on training. For example, what level of student is typically hired to staff a learning commons service desk (undergraduate, graduate, both)? Are there common 
training content areas for learning commons? Are there common sizes to staff teams? Given that many learning commons programs are still emerging, identifying the gaps in the literature and seeking answers can provide hiring, training, supervision, and assessment models for new learning commons librarians, coordinators, or supervisors. It can also help those looking to improve their learning commons training program.

\section{Methodology}

The purpose for this research project was to conduct an initial exploration around student hiring and training in learning and information commons in Canada and the United States. The intent of the survey was to learn more about training student staff who offer information at a desk as well as evaluate the success of student programs who offer this kind of help.

The research began by submitting a proposal for ethics approval at Queen's University. Before submitting the research study for ethics approval at Queen's, the authors consulted the Assessment Librarian at UBC Library to ensure that the respondents were guaranteed anonymity and that the questions of the survey were not misleading or unclear. The ethics committee at Queen's approved the survey in May 2011.

The survey (see Appendix A for a copy of the survey) was distributed to two listservs: CAN-LC (Canadian Learning Commons), which has 208 subscribers (mostly from Canada); and the American Library Association's Infocommons-L, which has 849 subscribers. The survey was addressed specifically to learning (or information) commons supervisors, coordinators, or librarians. Notable limitations to the approach of sending to these two listservs include that each list could have several members of a single learning/information commons and there is likely overlap in the subscriber base between the lists. Without access to the subscriber list, however, neither of these limitations could be examined further. The survey was sent on September 30, 2011, and remained open until Friday, October 17, 2011. A reminder was sent halfway through this time period. In our letter of intent for the survey, we indicated that the respondents did not need to identify themselves, but we did ask if they could answer the questions as frankly as possible. The respondents had the opportunity to withdraw without prejudice at any time with no adverse personal effect. The complete letter of intent is included in Appendix B.

\section{Survey and Results}

The results analysis includes answers from all respondents who took the Learning/Information Commons Student Staff survey in the 27-day period from Friday, September 30, 2011, to Thursday, October 27, 2011. Sixty-four completed responses were received.

Question 1 of the survey asked respondents to indicate whom they hire as student staff. The intention was to learn what level and type of university students are hired by learning commons and if there was consistency across different learning commons. Respondents could check all categories that applied. From the sixty-four respondents, 92 percent indicated that they hired undergraduate students, 53 percent indicated that they hire graduate students, 14 percent indicated that they hired students in library school, and 8 percent indicated "other." Results are illustrated in figure 1.

There were four responses in the "other" category, indicating that respondents hired college students; "ILRC Interns"; currently enrolled students; and second- and thirdyear technology institute students in their learning/information commons.

The second question asked respondents what method or format they used to train their student staff. Survey participants were asked to select the option(s) that applied to their training approach including in-person, peer-to-peer training, and online training. As shown in figure 2, 97 percent of survey respondents indicated that they deliver 


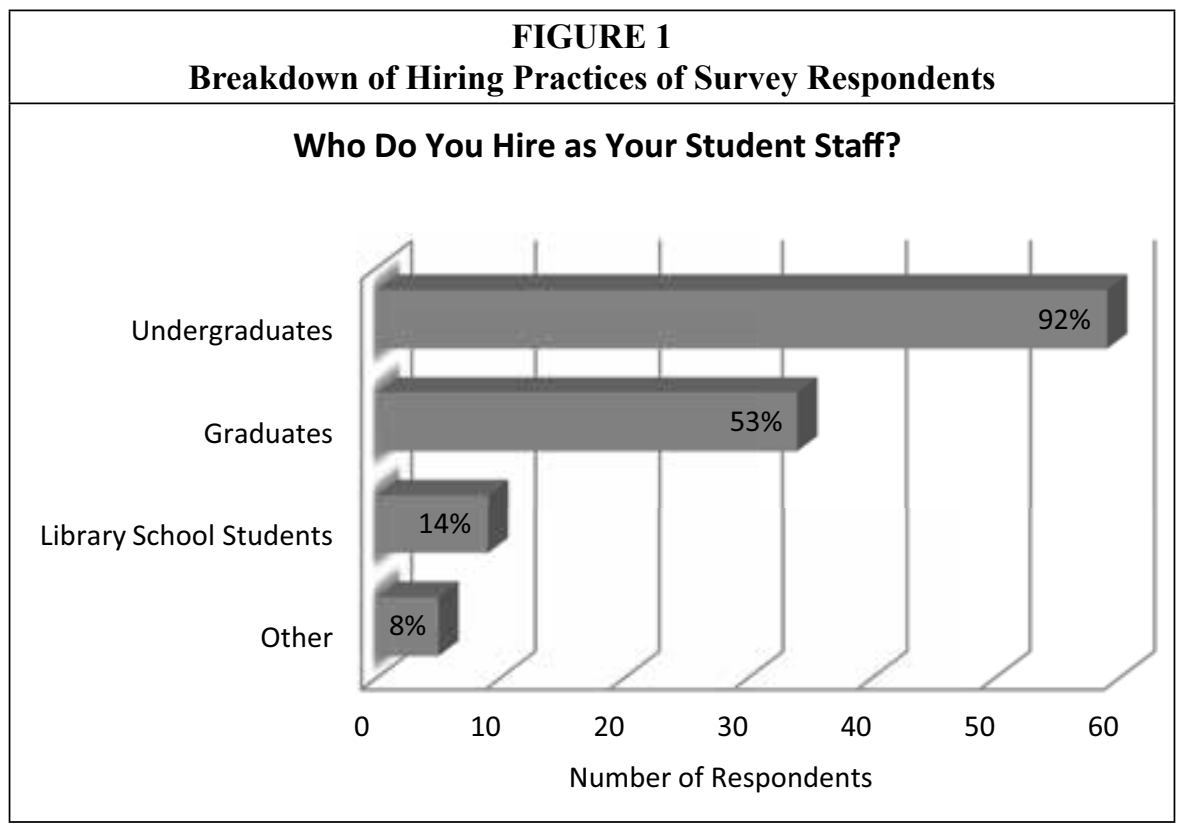

in-person training; 70 percent indicated they employed peer-to-peer training methods; and 34 percent used online training approaches.

The third question asked about the extent of training, in particular the number of days or hours of the training and if it was delivered beforehand or on the job. Responses to this question were open-ended. There were no clear trends in terms of the hours or length of training, with responses ranging from two hours to five days of formal training. Textual analysis of the responses showed some consistency in responses with respect to whether

\section{FIGURE 2}

Breakdown of Training Approaches of Survey Respondents

\section{How Do You Train Your Student Staff?}

Peer-to-peer Training

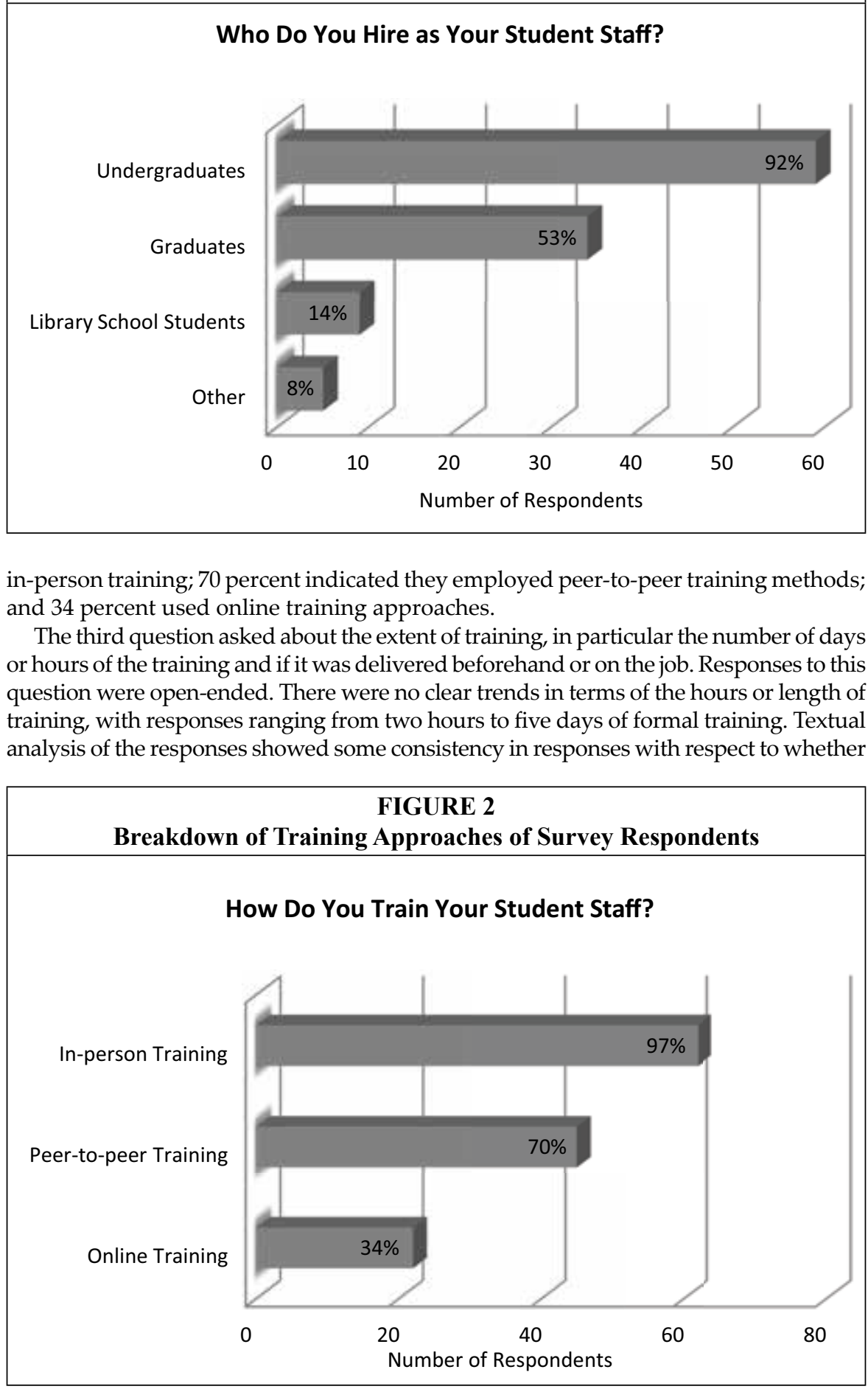

In-person Training 


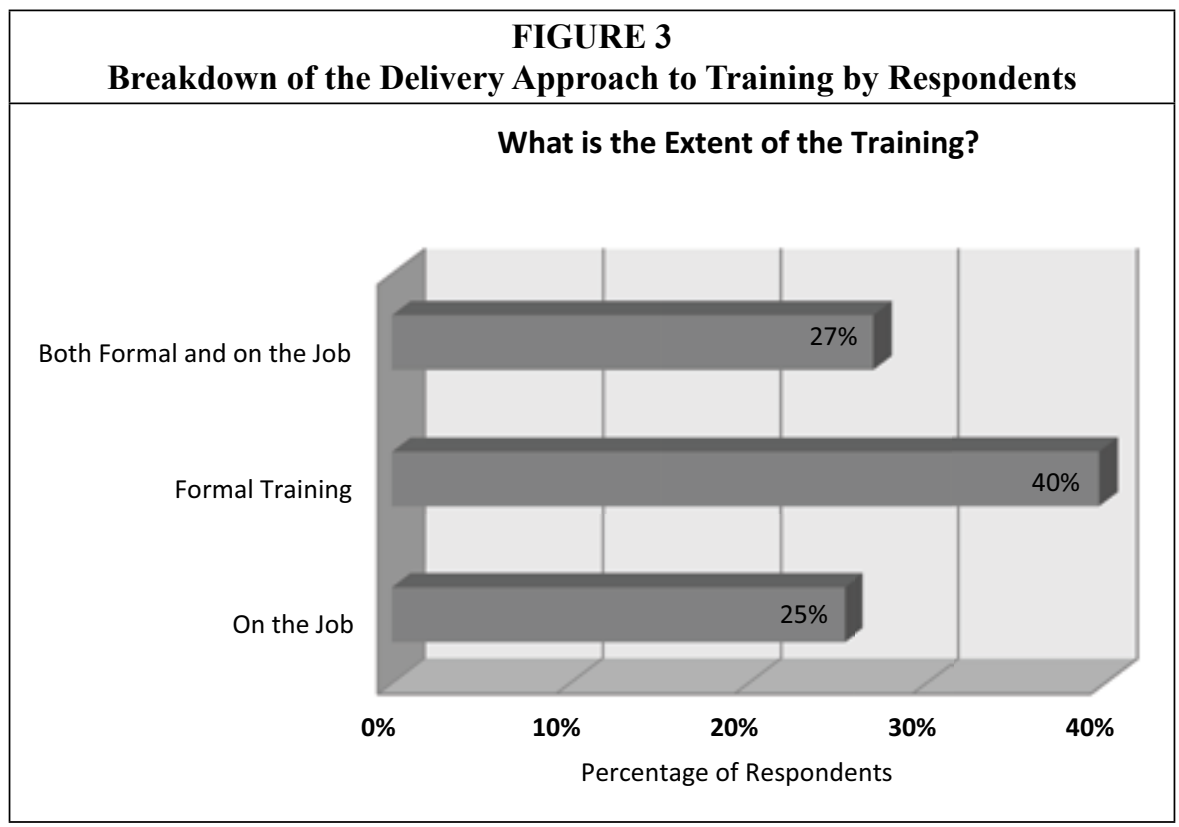

training was offered beforehand or on the job. As shown in figure 3, 40 percent of respondents mentioned that they offered formal training; 25 percent mentioned on-the-job training; and 27 percent mentioned offering a combination of formal and on-the-job training.

Question 4 asked participants to indicate the content of training from a list of options. Participants were asked to select all content categories that applied. The top three content areas of training for survey respondents were IT Support (72\%), general campus information (59\%), and library research skills (56\%). Figure 4 below provides a breakdown of survey responses.

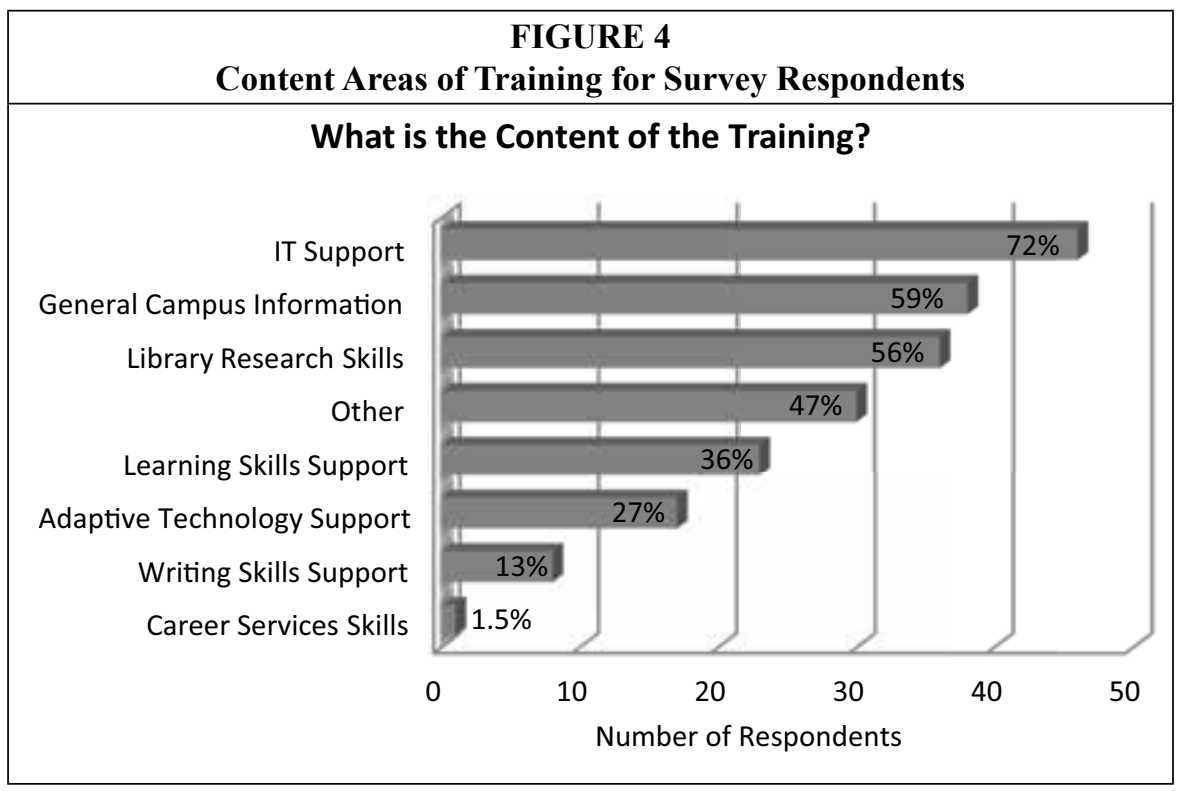


For this question, the "other" category was the fourth most popular response. Responses in the "other" category included:

- Communication skills

- Customer service training

- Writing skills training

- Learning skills support

- $\quad$ Room scheduling

- Circulation duties

- Copyright

Question 5 was a follow-up to the previous question, asking if respondents provided refresher or advanced training after initial training. A total of 81 percent of respondents provided refresher training and 19 percent did not.

Those survey respondents who indicated that they provided refresher training in question 5 were asked to specify what type of follow-up or advanced training was offered and how often. Responses to question 6 were open-ended. Content analysis of the responses to the open-ended questions was performed and involved examining responses, identifying themes, and assigning a score each time the theme was mentioned. Analysis of the responses revealed the following trends:

- 20 percent of respondents mentioned refresher training taking place in weekly or biweekly staff meetings

- 18 percent mentioned training once or twice per semester

- 14 percent mentioned continuous training on the job, as required

- 6 percent mentioned formal workshops offered throughout the term

- Training focused on topics covered in question 4, such as IT support, general campus information and library research skills

The seventh question of the Information/Learning Commons Student Staff Survey asked respondents to indicate how they ensured that questions are answered accurately by their staff. Responses to this question were open-ended. Content analysis of the responses to question 7 revealed the following trends:

- 27 percent of respondents mentioned pairing students with senior students or professional students

- 24 percent mentioned informal observation

- 14 percent mentioned training

- 14 percent mentioned satisfaction surveys or customer feedback

- 5 percent mentioned end-of-shift reports

- 10 percent mentioned referral

- 10 percent mentioned that they have no mechanism for ensuring accuracy of responses

Question 8 of the survey asked respondents to indicate if they hold regular staff meetings to review staff problems, issues, and questions with their team. Nearly three quarters $(73 \%)$ of respondents hold regular staff meetings; 27 percent do not.

To learn if there were any trends with respect to staff size of information/learning commons teams, question 9 asked participants to indicate how many students are employed by their commons. Answers to this question were open-ended and ranged from zero to 150 students. Analysis of the responses revealed that 39 percent of survey respondents employ one to fifteen students; 29 percent employ sixteen to thirty students; and 17 percent employ thirty-one to forty-five students. Figure 5 provides a breakdown of responses.

The average staff size across all survey responses was twenty-nine team members. Respondents indicating a staff size of twenty-five or more were responding on behalf of multiple programs within a learning commons environment (examples: writing center, tutoring, IT help desk). 


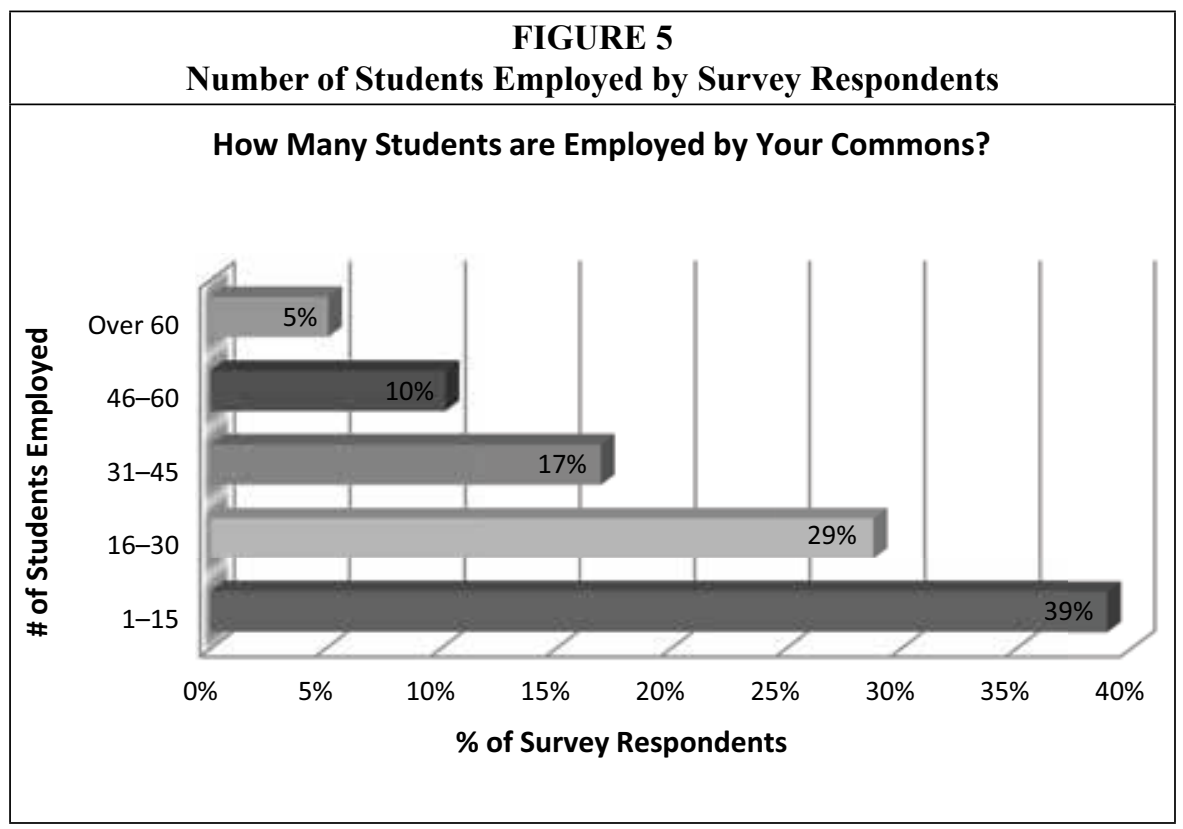

Question 10 asked survey respondents to indicate how many hours student staff in their learning commons work each week. As with question 9, survey responses were open-ended and varied significantly. Weekly hours ranged from one hour to thirty-five hours per week. An analysis of the responses revealed that 37 percent of student staff work six to ten hours per week and 37 percent work eleven to fifteen hours per week. Notably, where a range of hours were provided, a mean was calculated for the purpose of creating a chart to show the trends in responses (see figure 6).

Further analysis of results from question ten, showed the following trends:

- 52 percent of respondents reported fifteen hours per week or higher

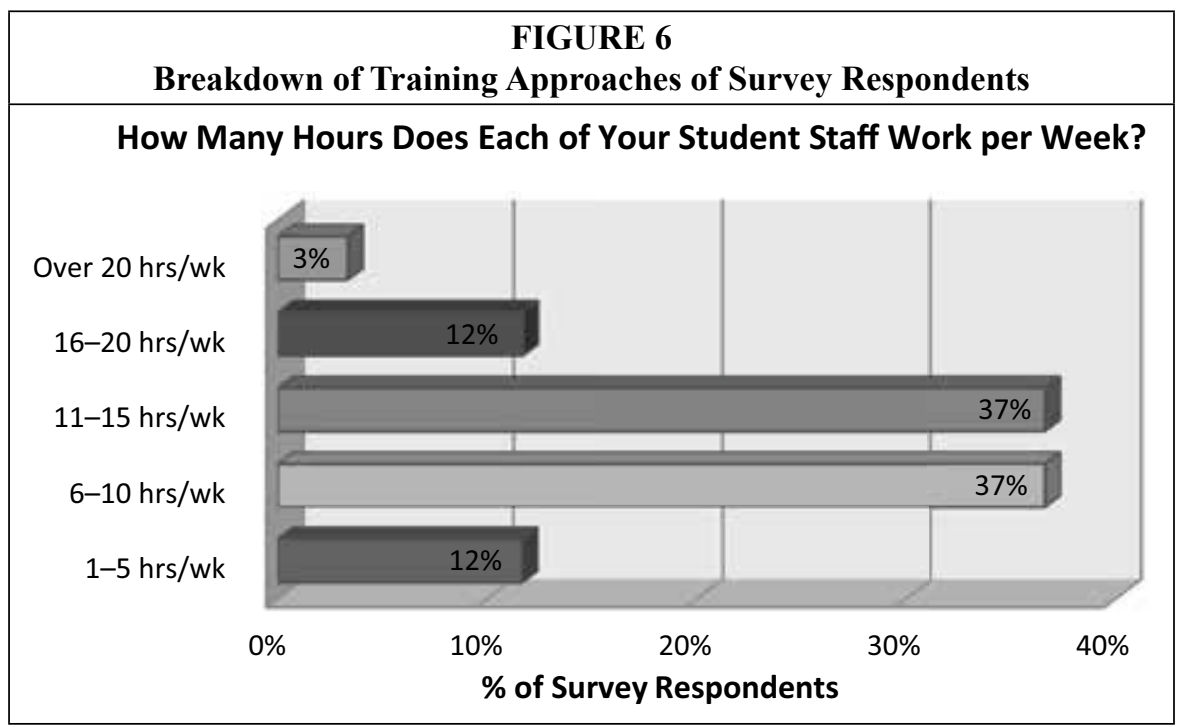


- 48 percent of respondents provided a range of hours

- 30 percent of respondents reported a range of ten or more hours

Question 11 asked respondents if their student staff worked all year (twelve months) or just during the academic year. Responses were open-ended. Analysis of responses indicated that 63 percent of student staff worked all year (twelve months) and 37 percent work the academic year only.

The final question of the survey asked respondents if they had additional comments. Responses were open-ended. Twenty-one survey participants provided comments. Survey comments highlighted the following:

- A need for more training for student staff

- The importance of clear policies, procedures, and guidelines

- The challenges and importance of screening and selection

Many respondents indicated multiple student groups (managed by different supervisors) working from their commons

That students appreciate the peer-to-peer support

The respondents are exploring cross-training as an option

Staff size and multiple partners in a learning commons environment

\section{Discussion}

While results from the study provide useful insight into how many learning commons work with their student staff, it is important to note the relatively low sample size. The sample size of 64 respondents means the data cannot claim to be representative of learning commons across North America. It should also be noted that using the CAN-LC (Canadian Learning Commons) and the American Library Association's Infocommons-L listservs to solicit responses inherently provides a convenience sample, which also limits the generalizability of results. Despite these limitations, the study provides groundwork for future research and a starting point for discussion around working with student staff in a Learning Commons environment. The discussion weaves in the local experiences of the authors to provide examples and details from two Learning Commons with over a decade of experience with student-led programs.

Given that many learning commons environments focus on first-year or undergraduate student support and emphasize the peer-support model, it is not surprising that 92 percent of survey respondents indicated that they hire undergraduates. What seems to set learning or information commons environments apart from traditional reference desks in academic libraries is the low percentage of library school students hired. Survey respondents indicated that only 14 percent hired library school students. The reason could be that they were answering on behalf of programs that do not require that expertise (that is, writing centers or tutoring programs); could indicate that they do not have library school students available; or could point to hiring practices emphasizing undergraduate peer support rather than library-focused expertise on the desk. An important limitation to note is the lack of demographic data about the institution, specifically if the institution has a Library and Information Studies program. Such information would provide a much richer set of data from which to analyze the results from question 1. Both the Queen's Learning Commons and UBC's Chapman Learning Commons hire almost exclusively undergraduate students. The motivation for this practice stems from the emphasis on, and recognized benefits of, the peer support model. At UBC's Chapman Learning Commons, while library school students are available, experience demonstrates that undergraduate students are better suited to the role since the focus of services is on first-year support. Undergraduate students are closer to this experience and better equipped to offer approachable, peer-to-peer support. 
Looking at training practices indicated by survey respondents, peer-to-peer and inperson training were the most popular answers. With the importance of the peer-support model in a learning/information commons environment, it is encouraging to see that 70 percent of respondents indicated peer-to-peer training as a preferred approach. While some supervisors, coordinators, and librarians may have concerns about the quality of training offered by student staff, the authors have found that, by creating effective training manuals, modules, lessons, and quizzes, returning student staff can provide quality training to their peers. The responses for online training, on the other hand, were relatively low at 34 percent. Both the Queen's Learning Commons and Chapman Learning Commons employ forms of online training, and it has been the experience of the authors that this method can be effective on many fronts. Online training can be offered in advance of in-person training to provide a foundation of knowledge and better prepare students for the deluge of information that often occurs during in-person training. Another benefit of this supplementary training approach is that it allows flexibility to hire students mid-year, in the event that a student needs to leave unexpectedly for a co-op work term, study-abroad program, or other opportunity. Online training can be conducted with online teaching tools such as Moodle, Blackboard, or WebCT-Vista. While the initial development of online training modules can be time-consuming, the long-term benefits are far-reaching, in terms of a highly trained staff team and a reduction of continuous refresher training on the more detailed information required of the job. If using course management systems is not feasible, online tools such as blogs, wikis, and intranets can also support the training of, and ongoing communication with, student staff.

Examining the responses on the extent of training, the wide range of responses is notable. While 92 percent of respondents provided training, the extent of training offered ranged from two hours to five days. The lack of clarity in this response points to a problem with the design of question 3. Specifically, the open-ended response led to difficulties with analysis and the inability to identify clear trends with respect to the number of hours/days that training was provided. Question 3 could be improved for future studies with a categorical approach that provides the option to indicate if training was done beforehand, on the job, or both; and a range of times to indicate the length of training.

While the question design resulted in difficulty to see trends, it was clear that there was a significant range in the length of training provided to students. With such a vast difference in responses, the depth of training would be impacted significantly. Even within the respective institutions of the authors, training across the library system varies widely. In the spirit of supporting the learning of both patrons and the student team itself, the results from this question point to a need for more consistency with training of student staff in a learning commons environment. This could be facilitated by the development of a list of competencies and standards for learning commons student staff. While each learning commons is different, the survey results indicate consistency among many learning commons around the content of training such as IT support, general campus information, and library research skills. Looking at the core competencies required for these common content areas, a competency inventory focused on digital and information literacy skills relevant to academic library environments could provide a useful foundation for developing and supporting staff skill development. If coupled with suggested training approaches, the development of such a resource could save tremendous time for learning commons supervisors, coordinators, and librarians by providing clear training guidelines and creative training ideas.

As indicated in the literature review, it is important to offer additional training for students. A total of 19 percent of survey respondents indicated that they did not provide refresher or advanced training. It has been the experience of the authors that the amount of information retained from training by student staff varies greatly and that ongoing 
training to reinforce skills and knowledge is essential for success of students in their role. Ongoing training can take a variety of forms, including formal training in staff meetings; creative games or quizzes to reinforce knowledge; and guest speakers from other departments to provide unique expertise. Examples applied by the authors include interactive quizzes in online course software; scavenger hunts requiring students to discover information essential for success in the position; and peer-led training on topics of interest for the team. As indicated in the literature, ${ }^{43}$ variety is the key when training students and for fostering a skilled student team. Ongoing training topics vary each year due to the expertise of the team and the questions being asked by patrons but typically include issues such as software training (such as Photoshop, Illustrator, MS Office), hardware training (for example, training on camcorders, iPads, or eBook readers), dealing with difficult patrons, microform use, and equipment circulation policies.

A method for determining the type of training required by the team is not only asking the student staff, but monitoring how questions are answered and looking for areas of improvement. According to survey responses, learning commons supervisors employ a variety of methods to ensure accuracy of responses (here are examples of some of these methods: pairing with senior students, informal observation, satisfaction surveys, and end-of-shift reports). For example, both authors require student staff to enter questions and responses into their statistics tracking software. At Queen's University, the student staff track their statistics with locally developed software. At UBC, the students use the DeskTracker ${ }^{\mathrm{TM}}$ library statistics system to document questions. By regularly monitoring the questions and responses entered by student staff into the statistics-tracking systems, areas of improvement are readily identified, and customized training modules are developed to increase the knowledge of the student team. For example, by reviewing the questions, it may be observed that troubleshooting questions (for technical issues, facilities questions, and the like) in the learning commons are not consistently referred by student staff to the correct contacts. Accordingly, a quiz would be developed with sample questions, and students would be asked to whom they would refer each question. The quiz would be administered and reviewed in a staff meeting, and a small prize would be offered to those who answered all questions correctly.

Staff meetings are often the most practical time to deliver ongoing training to student staff; with 73 percent of survey respondents indicating regular staff meetings, such an approach may be feasible for most learning commons environments. These staff meetings not only serve the purpose of training and information delivery, they also serve as an opportunity for team building and staff motivation. Given the importance of regular staff meetings, both the Queen's Learning Commons and UBC's Chapman Learning Commons host regular staff meetings (monthly and biweekly respectively) throughout the term, and attendance is required as part of the students' job contract. While approaches to staff meetings differ, both authors consider attendance at the staff meetings as paid work time (like a shift) and use this time for professional development, ongoing training, and team building. While finding a common meeting time with a large student team can be a difficult task that may require an early morning or late evening meeting time, the benefits in terms of staff knowledge and motivation are extensive.

Another goal for the survey was to learn more about the size of student teams and how they operated. Responses to question 9 of the survey revealed a dramatic range in size of staff teams, from one staff member to 150 student staff. While the intent of the survey was for respondents to answer on behalf of the student team they supervised directly, some respondents were answering on behalf of all programs offering services in their space. The lack of clarity in how participants responded to this question points to a flaw in the design of the question itself. Specifically, this question could be improved on a future study by specifying that participants respond only on behalf of the students 
they supervise directly (not on behalf of all programs) and also by providing ranges (like 1-5, 6-10) to choose from to indicate staff size, rather than an open-ended option. Clarifying the question would provide better context for analyzing the results, while providing ranges would provide a more consistent set of data to analyze.

Despite these limitations, the range in responses speaks to the extensive networks of students who offer services in a learning commons environment. Highlighting this range specifically, at the Queen's Learning Commons, one author directly supervises twelve students (Learning Commons Student Assistants), while over 100 students offer services out of the space, including writing support (peer tutors), peer coaching, circulation, peer mentoring, and text transcriptions for students with print disabilities. Similarly at UBC's Chapman Learning Commons, one author co-supervises sixteen students, while a total of ninety-five students offer IT support, writing assistance, peer coaching and tutoring out of the space.

Examining the responses to the question on how many hours each student staff member worked spoke to the variety of context in which students worked. While 49 percent of respondents indicated that each student worked ten hours per week or less, 51 percent of respondents indicated that each student staff member worked over ten hours. Given that the majority of respondents hire undergraduate students, the authors found these results surprising, since both work at institutions where staff funding models and union regulations dictate a maximum of 10-12 hours per week for part-time students. For future surveys exploring this question, a helpful follow-up question would be whether these student staff were full-time or part-time students; if some were employed on full-time co-op work terms or internships; and if the learning commons operated within a union environment. Similar to the limitations of question 9, question 10 could also be improved for future studies by providing a range of options to choose from (such as 1-5, 6-10) rather than providing an open-ended response.

The final survey question offered perspective on the number of learning commons that hire staff for twelve months per year versus those who only hired for the academic term. It has been the experience of the authors that service points in learning commons often hire year round, while tutoring and learning support partners (that is, writing centers) do not offer year-round services. Looking at training, a benefit of hiring staff year round is that these students often become role models and leaders to incoming student staff. At both UBC's Learning Commons and Queen's Learning Commons, the summer student team play a central role in developing and delivering training to the incoming fall team and conduct extensive work updating online training modules and documents.

An issue not addressed in the survey, but one that is important to address with further research, is the topic of assessment. How are peer-educator opportunities, training sessions, and service levels assessed in the Learning Commons? How can we measure the impact of peer-led programs both on the students they serve and the students employed by the program? At the University of British Columbia, assessment of the student-staff programs is done through performance reviews that allow for feedback from each student about their experience in the program as well as a "rapid-fire wrap-up" session at the end of each term where the entire student team gets together and shares their thoughts on a number of strategic questions about the Learning Commons. At Queen's and UBC, paper surveys are distributed at the end of annual training programs and are a source of feedback for continual improvement. In addition, graduating student staff at Queen's University meet one-on-one with the coordinator to give their feedback about their experiences as peers in the learning commons. All strategies have been effective means for improving programs in our respective learning commons; however, more work needs to be done to formalize assessment strategies and also more effectively communicate findings. 
Overall, the results from this exploratory study provide a foundation for future research and provide a glimpse at how several learning commons work with their student staff. Limitations include the limited sample size, the convenience sample, lack of institutional demographic data, and the need to provide categorical options for questions 3, 9, and 10 to avoid challenges with data analysis. It is hoped that the challenges revealed with the approach to this survey will serve to inform future studies and highlight opportunities for improvement.

\section{Conclusion}

Learning commons are complex environments. While the survey demonstrates many similarities between learning commons environments, each learning commons has different partnerships and collaborative infrastructures, which may lead to diverse and sometimes layered organizational structures. Overall, results highlighted that supervisors invest significant time and resources into training student staff, and there is consistency with the type of training provided despite significant variations in team sizes, demographics, and operations. The survey results also showed that the peer model is prominent in learning commons environments in North America and beyond. Clearly, student staff are fundamental to the operation of learning or information commons environment in academic libraries. The benefits of peer-to-peer service are well documented, particularly since university and college students are often more comfortable approaching a fellow student than a professional for help.

Despite the benefits of hiring student staff, the process of hiring, training, and supervising student staff requires a significant time investment, particularly given high turnover of student staff due to graduation, internships, and semesters spent studying abroad. The implications of this reality on training means that it is important to have a flexible but comprehensive training program that can be offered at various points in the academic term - for example, supplementary online training may provide this kind of flexibility. Results also point to the importance of ongoing training, particularly given the emphasis on hiring undergraduate students, who typically do not have the same level of skills, knowledge, or expertise offered by full-time staff or graduate students.

For new learning commons librarians, coordinators, or supervisors, or those looking to reinvigorate their training program, this study offers key training content areas that may be helpful to emphasize in shaping a training program: IT support, general campus information, and library research skills. The survey results also provide examples of training approaches (online, in-person, peer-to-peer) and strategies for ensuring the quality of responses for student staff (pairing with senior students, informal observation, satisfaction surveys, end-of-shift reports). Ideas for improving training and staff competencies include developing a competencies inventory, tracking student staff responses to questions (to be reviewed regularly), and customizing ongoing training accordingly.

As a next step to this research, it is hoped that more work can be done to connect staff from various learning commons environments in North America and beyond to share expertise, resources, and approaches to fostering a skilled and motivated student team. As part of this process, it would be helpful to develop a shared repository of training resources that may be adapted to other learning commons environments. Such resources could help reduce the time and effort invested in developing unique training programs and offer inspiration and a fresh perspective in terms of rejuvenating an existing training program. While the ongoing process of hiring, training, and mentoring new students in a learning commons environment can be a daunting and challenging task, the rewards to both students and supervising staff are immeasurable. Investing in student training not only improves service in a learning commons; it also offers personal growth and professional development opportunities that serve students well beyond graduation. 


\section{APPENDIX A. Letter of Intent}

\section{Students in the Learning (or Information) Commons}

Dear Learning (Information) Commons Supervisor, Coordinators, or Librarians,

You are invited to participate in research about students in the Learning/information Commons conducted by Ms. Nathalie Soini (Queen's University, Queen's Learning Commons) and Ms. Julie Mitchell (University of British Columbia, Chapman Learning Commons). The purpose of this research is to gain a better understanding of how students are trained to answer questions in an academic setting. Moreover, our research will also help all coordinators, supervisors, or librarians with further training and quality assurance in their Commons.

The research timeline will be as follows:

E-mail listservs with Letter of Intent and Survey - end of September 2011

Survey deadline-end of October 2011

Analysis of data-November-December 2011

The survey should not take more than 15 minutes to complete. Your identity will remain anonymous unless you choose to identify yourself. We would appreciate it if you could answer all material as frankly as possible. However, you should not feel obliged to answer any materials that you find objectionable or that makes you feel uncomfortable. You can withdraw without prejudice at any time with no adverse personal effect. If you withdraw, please contact Nathalie Soini (soinin@queensu.ca) and all of your data entered will be removed permanently. All data will be stored on a server at the University of British Columbia and at Queen's University. Only the primary researchers will have access to this data. All data will be removed from the servers after 2 years. The data compiled from the survey may be published in professional journals or presented at conferences, but any such presentations will be of general findings and will not breach individual confidentiality (if you have chosen to remain anonymous). If you complete the survey, please contact Nathalie Soini to receive a copy of the study findings.

Any questions about study (data and survey) may be directed to:

Nathalie Soini

Learning Commons Coordinator

Queen's University

Kingston, $\mathrm{ON}$

(613) 533-6000 x75566

soinin@queensu.ca

Any ethical concerns about the study may be directed to the Chair of the General Research Ethics Board at chair.GREB@queensu.ca or (613) 533-6081.

This study has been granted clearance according to the recommended principles of Canadian ethics guidelines and Queen's University.

Again, thank you for your interest in participating in this research study. 


\section{APPENDIX B. Learning/Information Commons Student Staff Research}

\section{ONLINE SURVEY}

1. Whom do you hire as your student staff? (Choose all that apply)

- Undergraduates

- Graduates

- Library school students

- Other

\section{TRAINING}

2. How do you train your student staff? (Choose all that apply)

- In-person training

- Online training

- Peer-to-peer training

3. What is the extent of the training? (How many days/hours and is it done on the job or beforehand?)

4. What is the content of the training? (Choose all that apply)

- Library research skills

- IT support

- Learning skills support

- Writing skills support

- Adaptive technology support

- Career services skills

- General campus information

- Other

5. After initial training, do you provide refresher or advanced training? Yes/No

6. If yes, what do you offer and how often?

7. How do you ensure that questions are answered accurately by your staff?

8. Do you hold regular staff meetings to review staff issues, problems, questions, etc.? Yes/No

9. How many students are employed by your Commons?

10. How many hours does each of your students work per week?

11. Do your students work all year (12 months) or only during the academic year?

12. Other comments?

\section{Notes}

1. Joan K. Lippincott, "Linking the Information Commons to Learning," in Learning Spaces, ed. Diana G. Oblinger (Washington, DC: Educause, 2006), 7.3.

2. Allison I. Faix et al., "Peer Reference Redefined: New Uses for Undergraduate Students," 
Reference Services Review 38, no. 1 (2010): 90-107.

3. Andrea G. Stanfield and Russell L. Palmer, "Peer-ing into the Information Commons: Making the Most of Student Assistants in New Library Spaces," Reference Services Review 38, no. 4 (2010): 634-46.

4. W.F. Heinlein, "Using Student Assistants in Academic Reference," Reference Quarterly 15, no. 4 (1976): 323.

5. Orrin B. Powell, "The Student Who Assumes Counseling Responsibilities," Faculty in College Counseling, ed. Melvene Draheim Hardee (New York: McGraw-Hill, 1959).

6. Stephanie R. Ganser and Tricia L. Kennedy, "Where It All Began: Peer Education and Leadership in Student Services," New Directions for Higher Education, no. 157 (2012): 17.

7. Debbi Dinkins and Susan M. Ryan, "Measuring Referrals: The Use of Paraprofessionals at the Reference Desk," Journal of Academic Librarianship 36, no. 4 (2010): 279.

8. Stanfield and Palmer, "Peer-ing into the Information Commons," 634-46; Faix et al., "Peer Reference Redefined," 90-107; Theresa S. Arndt, "Reference Service Without the Desk," Reference Services Review 38, no. 1 (2010): 71-80.

9. Ruth E. Neal et al., "Peer Education in the Commons: A New Approach to Reference Services," Medical Reference Services Quarterly 29, no. 4 (2010): 405-13; Frances O'Neil and Jenny Comley, "Models and Management of Student Employees in an Australian University Library," Australian Academic \& Research Libraries 41, no. 2 (2010): 100-12; James K. Elmborg and Sheril Hook, Centers for Learning: Writing Centers and Libraries in Collaboration, (Chicago: Association of College and Research Libraries, 2005), 231; Karin de Jager, "Navigators and Guides: The Value of Peer Assistance in Student Use of Electronic Facilities," VINE: The Journal of Information and Knowledge Management Systems 34, no. 3 (2004): 109; Jacqueline Borin, "Training, Supervising, and Evaluating Student Information Assistants," Reference Librarian 34, no. 72 (21): 195-206.

10. Arthur P. Young, "Student Assistants: A Report and a Challenge," Reference Quarterly 9, no. 4 (1970): 295-97.

11. Joseph B. Cuseo, The Freshman Orientation Seminar: A Research-Based Rationale for Its Value, Delivery, and Content. The Freshman Year Experience (Columbia: Center for the Study of the Freshman Year Experience, University of South Carolina, 1991): 9.

12. O'Neil and Comley, "Models and Management of Student Employees," 104.

13. Jaime L. Shook and Jennifer R. Keup, "The Benefits of Peer Leader Programs: An Overview from the Literature," New Directions for Higher Education, no. 156 (2012): 5-16.

14. Shook and Keup, "The Benefits of Peer Leader Programs," 5-16.

15. Ibid.; Alexander W. Astin, "Student Involvement: A Developmental Theory for Higher Education," Journal of College Student Personnel 25, no. 4 (1984): 297-308.

16. Ernest T. Pascarella and Patrick T. Terenzini, How College Affects Students: A Third Decade of Research, vol. 2, (San Francisco: Jossey-Bass, A Wiley Imprint, 2005): 518.

17. Shook and Keup, "The Benefits of Peer Leader Programs," 5-16.

18. Brian O'Sullivan, "Organizing, Leading and Managing Student Services," Achieving Student Success: Effective Student Services in Canadian Higher Education, ed. Donna Gail Hardy Cox and Charles Carney Strange (Montreal: McGill-Queen's University Press, 2010): 179.

19. Astin, "Student Involvement," 297-308.

20. Ibid.

21. Pascarella and Terenzini, How College Affects Students, 133.

22. O'Neil and Comley, "Models and Management of Student Employees," 101.

23. Ruth Sara Connell and Patricia J. Mileham, "Student Assistant Training in a Small Academic Library," Public Services Quarterly 2, no. 2/3 (2006): 69-84.

24. Stanfield and Palmer, "Peer-ing into the Information Commons," 636-37.

25. Faix et al., "Peer Reference Redefined," 103.

26. Ganser and Kennedy, "Where It All Began," 17-29.

27. Faix et al., "Peer Reference Redefined," 94.

28. Stanfield and Palmer, "Peer-ing into the Information Commons," 635.

29. Connell and Mileham, "Student Assistant Training in a Small Academic Library," 74.

30. Michael D. Kathman and Jane McGurn Kathman, Managing Student Employee in College Libraries, 3rd ed. (Chicago: College Library Information Packet Committee, College Libraries Section, Association of College and Research Libraries, 2006).

31. Borin, "Training, Supervising, and Evaluating Student Information Assistants," 195-206.

32. Borin, "Training, Supervising, and Evaluating Student Information Assistants," 199.

33. Nancy E. Adams and James B. Young, "Users Learning from Users: Building a Learning Commons from the Ground Up at a New University," College and Undergraduate Libraries 17, no. 2/3 (2010): 154 .

34. Ibid.

35. Faix et al., "Peer Reference Redefined," 90-107; Stanfield and Palmer, "Peer-ing into the 
Information Commons," 634-46.

36. George D. Kuh, "Guiding Principles for Creating Seamless Learning Environments for Undergraduates," Journal of College Student Development 37, no. 2 (1996): 135-48.

37. Matthew R. Wawrzynski, Carl L. LoConte, and Emily J. Straker, "Learning Outcomes for Peer Educators: The National Survey on Peer Education," New Directions for Student Services 133 (2011): 24.

38. Shook and Keup, "The Benefits of Peer Leader Programs," 9.

39. Jennifer Latino and Catherine M. Unite, "Providing Academic Support through Peer Education," New Directions for Higher Education 157 (2012): 39.

40. Cuseo, The Freshman Orientation Seminar.

41. William Curran, "Reflections on the 8Rs Report and the Academic Library Community," Feliciter 52, no. 2 (2006): 72.

42. Stanfield and Palmer, "Peer-ing into the Information Commons," 638

43. Borin, "Training, Supervising, and Evaluating Student Information Assistants," 195-206;

Faix et al., "Peer Reference Redefined," 90-107. 